\title{
The capacity of refugia for conservation planning under climate change
}

\author{
Gunnar Keppel ${ }^{1 *}$, Karel Mokany ${ }^{2}$, Grant W Wardell-Johnson ${ }^{3}$, Ben L Phillips ${ }^{4,5}$, Justin A Welbergen ${ }^{5,6}$, \\ and April E Reside ${ }^{5}$
}

\begin{abstract}
Refugia - areas that may facilitate the persistence of species during large-scale, long-term climatic change are increasingly important for conservation planning. There are many methods for identifying refugia, but the ability to quantify their potential for facilitating species persistence (ie their "capacity") remains elusive. We propose a flexible framework for prioritizing future refugia, based on their capacity. This framework can be applied through various modeling approaches and consists of three steps: (1) definition of scope, scale, and resolution; (2) identification and quantification; and (3) prioritization for conservation. Capacity is quantified by multiple indicators, including environmental stability, microclimatic heterogeneity, size, and accessibility of the refugium. Using an integrated, semi-mechanistic modeling technique, we illustrate how this approach can be implemented to identify refugia for the plant diversity of Tasmania, Australia. The highest-capacity climate-change refugia were found primarily in cool, wet, and topographically complex environments, several of which we identify as high priorities for biodiversity conservation and management.
\end{abstract}

Front Ecol Environ 2015; 13(2): 106-112, doi:10.1890/140055 (published online 29 Jan 2015)

$\mathrm{R}$ efugia are locations where species may retreat (or migrate) to and persist in during large-scale and longterm climatic change; species therein have the potential to recolonize the surrounding areas should the external climatic conditions become favorable again (Keppel et al. 2012). Thus, refugia offer a suite of abiotic attributes - in time and space - suitable for particular species. These habitats become critical when conditions in the surrounding landscape no longer support the species (Ashcroft 2010; Keppel and Wardell-Johnson 2012). Ongoing anthropogenic climate change is rapidly altering environmental

\section{In a nutshell:}

- Refugia are habitats to which species can retreat in the face of climatic and other types of environmental change, thereby allowing them to persist

- The capacity of climate refugia must be determined to prioritize the most important refugia for conservation efforts

- We propose a framework to prioritize climate-change refugia effectively

- We use high-resolution spatial data on plant diversity and topography from Tasmania, Australia, to demonstrate how this framework can be applied to identify the most important climate-change refugia

\footnotetext{
${ }^{1}$ School of Natural and Built Environments and Barbara Hardy Institute, University of South Australia, Adelaide, Australia *(Gunnar.Keppel@unisa.edu.au); ${ }^{2}$ CSIRO Land and Water Flagship, Canberra, Australia; ${ }^{3}$ Department of Environment and Agriculture, Curtin University, Perth, Australia; ${ }^{4}$ Department of Zoology, University of Melbourne, Parkville, Australia; ${ }^{5}$ Centre for Tropical Biodiversity and Climate Change, James Cook University, Townsville, Australia; ${ }^{6}$ Hawkesbury Institute for the Environment, University of Western Sydney, Richmond, Australia
}

conditions, with considerable impacts on the distribution and ecology of species and ecosystems (Parmesan and Yohe 2003; Rosenzweig et al. 2008). As a result, refugia are becoming increasingly important in conservation planning (Loarie et al. 2008; Klein et al. 2009) and may offer the only means of survival for many species.

Identifying the location and spatial extent of future refugia, and quantifying the abiotic attributes that may protect particular species (henceforth referred to as the "capacity" of refugia), are essential to realizing their potential for helping species adapt to climate change (Keppel and Wardell-Johnson 2012; Reside et al. 2014). Here we propose a three-step framework that (1) defines the scope, scale, and resolution of potential refugia; (2) identifies potential refugia and quantifies their attributes; and (3) prioritizes potential refugia according to their conservation importance (Figure 1). We demonstrate the usefulness of this framework by applying it to identify climate-change refugia for maintaining native plant diversity of the State of Tasmania, Australia, using a semi-mechanistic, community-level biodiversity modeling approach that combines both correlative and process-based components (Mokany and Ferrier 2011; Mokany et al. 2012).

\section{Defining scope, scale, and resolution}

What constitutes a refugium depends on the temporal and spatial scales relevant to the persistence of the target species, as well as on the specific threats to the species. There are considerable differences in the types and magnitudes of climate-change threats in different regions (Solomon et al. 2007). Species also respond individually to changes in climatic variables (Stewart et al. 2010), and will therefore likely have varying requirements for refugia. For 
example, although warming temperatures are a major concern globally, cold-adapted species in mountainous regions and at higher latitudes are especially sensitive to such shifts (Rosenzweig et al. 2008; Ackerly et al. 2010). Refugia are dynamic entities that will change in both size and resilience as regional climate changes (Hampe and Petit 2005), and it is therefore essential to define relevant geographic and temporal scales clearly.

Defining the geographic scale of a refugium will involve deciding both the extent of the area to be investigated and the resolution of the topographic and climatic data required. The former will depend greatly on current and potential future distributions of the target species, while the latter will be determined by the target species' habitat requirements. Downscaling coarse-scale climatic models to finer resolutions through the use of detailed topographic maps and microclimatic data may be required for this process (Austin and Van Niel 2011; Franklin et al. 2013; Storlie et al. 2013), but the resulting fine-grain environmental layers may still contain inaccuracies due to regional weather patterns (eg wind speed or temperature inversions; Ashcroft et al. 2009).

From a conservation planning perspective, it will first be necessary to outline a management time frame over which to define a refugium. Because refugia are meant to protect species against long-term changes, this time span should generally be as long as possible. However, the uncertainty associated with climate predictions increases over time, with climate models' trajectories of atmospheric greenhouse-gas emissions becoming increasingly divergent and unreliable. Because the projections of climate-change impacts beyond the next century are tenuous (Kujala et al. 2013), the temporal scale of analysis for identifying future refugia should not exceed 100 years. Such a limited projection period is less than one generation for many long-lived organisms (eg Lara and Villalba 1993), and is unlikely to include the most extreme conditions that could occur. Current efforts to identify refugia based on projections are therefore inherently limited by their temporal scale.

\section{Scope, scale, and resolution for identifying Tasmanian refugia}

The State of Tasmania consists of one large and several smaller islands (total area $=68401 \mathrm{~km}^{2}$ ) to the southeast of mainland Australia (latitude $42^{\circ} 01^{\prime} \mathrm{S}$, longitude $146^{\circ} 36^{\prime}$ E). Our analysis extends previous research, which applied a semi-mechanistic macroecological modeling approach - M-SET (Metacommunity - Space, Environment, Time) - to project climate-change outcomes for the entire Tasmanian flora (2051 species) distributed among a variety of habitats (Figure 2) at fine spatial (250-m grid cell) and temporal (annual) scales (Mokany et al. 2012).

Given that rare species are at greater risk of extinction under climate change and are typically the primary target for conservation (Thomas et al. 2004; Malcolm et al. 2006), we focused our analysis on refugia for "less widespread" Tasmanian plant species. We defined these "less widespread" species as those whose current (as of 2010) estimated area of occurrence is in the lower three quartiles of all Tasmanian plant species (1538 of the total 2051 species). These include many species endemic to Tasmania, such as the King Billy pine (Athrotaxis selaginoides), huon pine (Lagarostrobos franklinii), celery-top pine (Phyllocladus aspleniifolius), and Australia's only native winter-deciduous species, the tanglefoot beech (Nothofagus gunnii) (Figures 2 and 3 ).

The overlap of refugia for multiple target species provides key areas for prioritization with broad applicability for conservation. Our analysis considers the projections from two climate-change models - CSIRO mk3.5 (Commonwealth Scientific and Industrial Research Organisation's global climatic model) and MIROC3.2 (medres) (Model for Interdisciplinary Research on Climate) - run for the A2 emission scenario, which assumes a continued economic (and less environmental) 

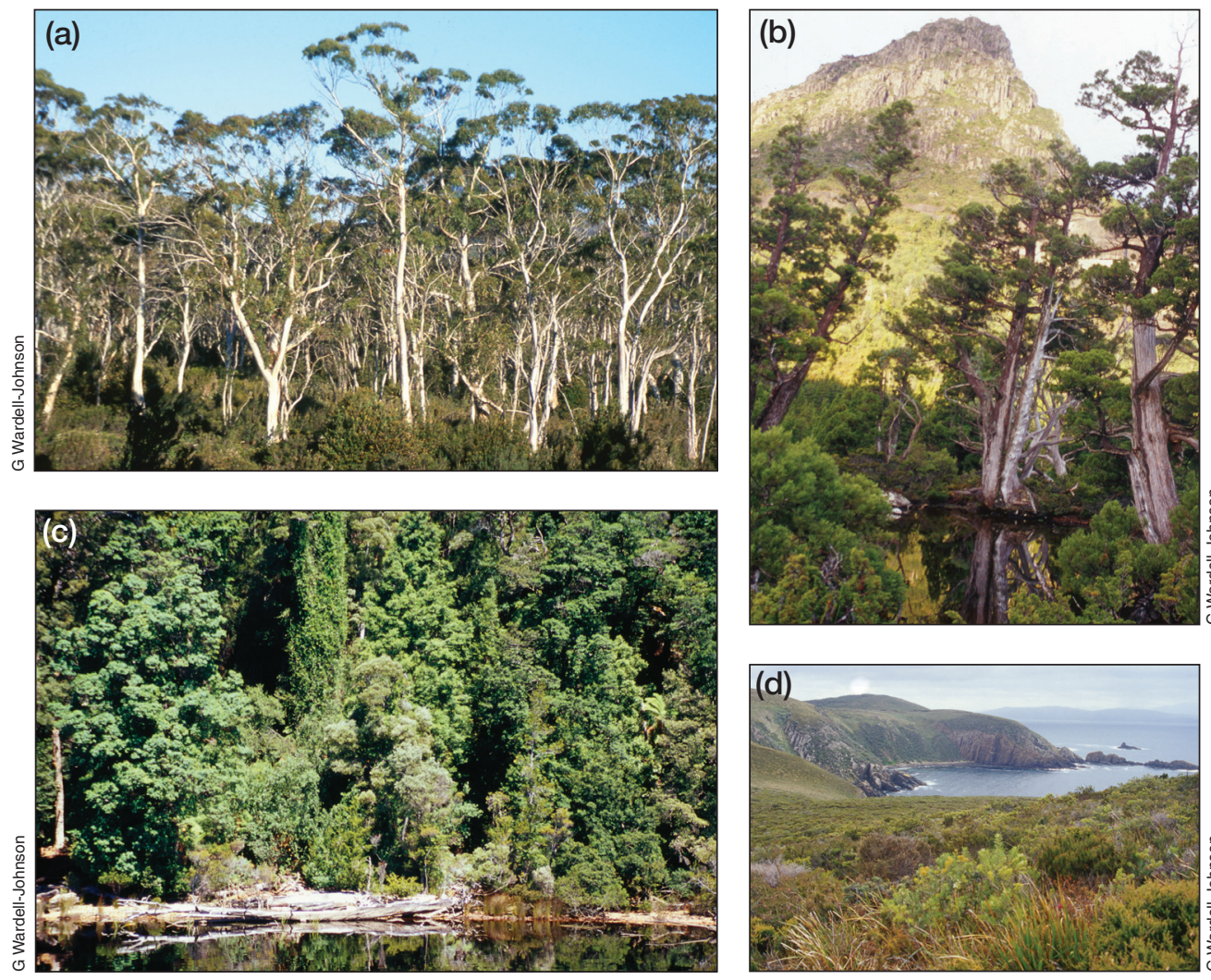

Figure 2. Four notable Tasmanian habitats and associated species include: (a) open snow gum (Eucalyptus pauciflora) forest of the south-central plateau; (b) alpine habitat of the endemic tanglefoot beech (Nothofagus gunnii) and King Billy pine (Athrotaxis selaginoides); (c) rainforest and riverine habitat notable for the endemic huon pine (Lagarostrobos franklinii), celery-top pine (Phyllocladus aspleniifolius), and horizontal scrub (Anodopetalum biglandulosum); and (d) coastal heath habitat.

focus with regional development. The climate projections were dynamically downscaled to $0.1^{\circ}$ using the CSIRO stretched-grid global atmospheric model (CCAM: Conformal Cubic Atmospheric Model; Corney et al. 2010; Grose et al. 2010). Our time horizon is set to 2100, this being the maximum time span for which future climate projections were available. Both climate models project similar average changes in annual precipitation between the present and $2100(+5 \%$ and $+2 \%$ for CSIRO mk3.5 and MIROC3.2, respectively), but MIROC3.2 projects substantially less intense warming (change in mean annual temperature $+3.24{ }^{\circ} \mathrm{C}$ and $+2.76^{\circ} \mathrm{C}$ for CSIRO mk3.5 and MIROC3.2, respectively).

\section{Identification and quantification}

There has been considerable progress recently in identifying potential future refugia (Ashcroft et al. 2012; Keppel et al. 2012). Historical refugia have mostly been identified using ecological, genetic, and paleobiological patterns (Keppel et al. 2012). However, these methods may be of limited relevance for identifying future refugia, because past climatic changes differ from those occurring now (Williams et al. 2007). For instance, in Tasmania some historical refugia have been identified for the last glacial maximum through Earth's surface; Sandel et al. 2011) may also be used to identify refugia. Areas with low climate-change velocities are often important historical refugia and may therefore be important future refugia as well (eg Sandel et al. 2011).

Although any location in a landscape may be a potential refugium for some species at some point in time, the capacity of various locations to act as refugia will differ widely. Potential capacity will depend primarily on the degree of climatic buffering provided (Ashcroft et al. 2012) but also on the ability of the location to sustain sufficiently large populations, as well as on refugial accessibility, given the current distribution of target species. The influence of these attributes on capacity can be quantified by evaluating the environmental stability, microclimatic heterogeneity (the variability of climate at fine scales, often due to topographic features), size, and accessibility of refugia.

\section{Environmental stability}

The ability to provide environmental conditions that are no longer available in the surrounding landscape - a key characteristic of refugia (Keppel et al. 2012) - may be facilitated by buffering local "interior" conditions from regional "exterior" conditions; this is often a function of local topography. Cold-air pooling (the formation of a 
shallow and cooler air layer near the ground) is a well-documented case of climatic buffering and occurs commonly in sheltered mountain valleys, mostly during winter months and at night (eg Daly et al. 2010). While such cold-air pooling will reduce the impacts of regional climatic warming locally, the buffering capacity of refugia would still be influenced by regional trends. Quantifying the degree to which local environmental conditions will change (ie the environmental stability of the refugium) would provide a key indicator of the potential capacity of that habitat.

\section{Microclimatic heterogeneity}

Topographical complexity may create unique microclimates through cooling of air with increasing altitude, movement of water along slopes, and shading of solar radiation (Dobrowski 2011; Ashcroft et al. 2012). Microclimatic heterogeneity is likely to increase the chances of survival for species, because the probability that a suitable climate will be present at any point in time increases with increasing diversity of microclimates. Microclimatic variability is therefore an indicator of the capacity of refugia (Ashcroft et al. 2012). Indeed, microhabitat variation has been linked to both species survival (eg Ohlemüller et al. 2008) and habitat quality (eg Weiss et al. 1988).

\section{Size}

When calculating refugial capacity, size is important because it defines the ability of a refugium to sustain viable populations of target species. The minimum size of a refugium will depend on the size and ecology of the species (Ashcroft et al. 2009). Furthermore, refugia may change in spatial extent with changing climatic conditions over time. Larger refugia are more likely to support larger populations and could also facilitate the conservation of species requiring greater range sizes (Gaston and Blackburn 1996). Such generalizations allow the rapid inclusion of refugium size into capacity appraisal, which may be desirable if there is a paucity of detailed information on the target species.

\section{Accessibility}

Lack of knowledge about the rate at which populations will be able to shift their ranges to keep pace with anthropogenic climate change (eg Chen et al. 2011) is a major disadvantage when trying to identify suitable refugia. In the context of contemporary conservation planning, the apparent slowness with which many species appear to have moved out of their refugia after the last glacial maximum
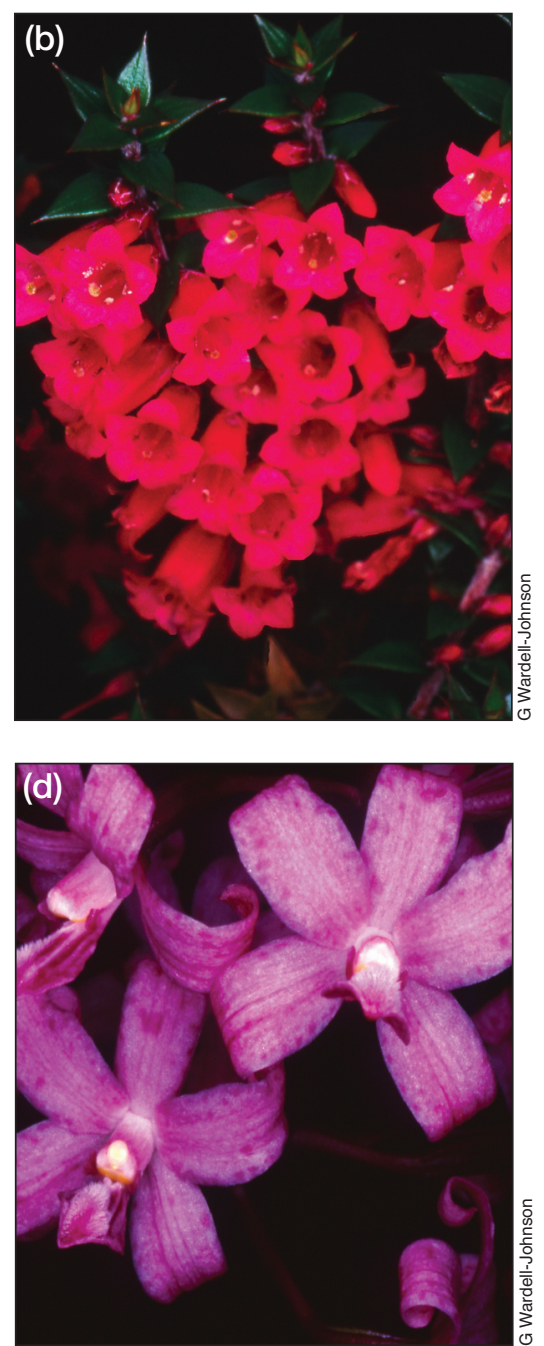

Figure 3. Examples of Tasmanian vascular plant species included in (ie "less widespread" - see text for definition) and excluded from (ie "widespread") modeling. "Less widespread" species either are endemic to Tasmania (eg [a] Richea dracophylla - Ericaceae) or also occur outside Tasmania (eg [b] Epacris impressa - Ericaceae), where they may be widespread and abundant. Excluded, "widespread" species may also be endemic to Tasmania (eg [c] Bellendena montana - Proteaceae) or not (eg [d] Dipodium roseum - Orchidaceae).

suggests that predicted rates of climate change will likely exceed species' ability to keep pace (Svenning and Skov 2007). Nevertheless, the closer the species is to the refugium, the smaller the required range shift will be, and hence the greater the chances of survival. Thus, the proximity of potential future refugia to the target species' current range is an important consideration when prioritizing areas for conservation, especially for small-range species, which are likely to be more vulnerable to changing conditions (Ohlemüller et al. 2008).

\section{Identifying and quantifying refugia for Tasmanian plants}

We used a dynamic macroecological modeling approach - incorporating multiple indicators (environmental stability, microclimatic heterogeneity, and accessibility) - to 


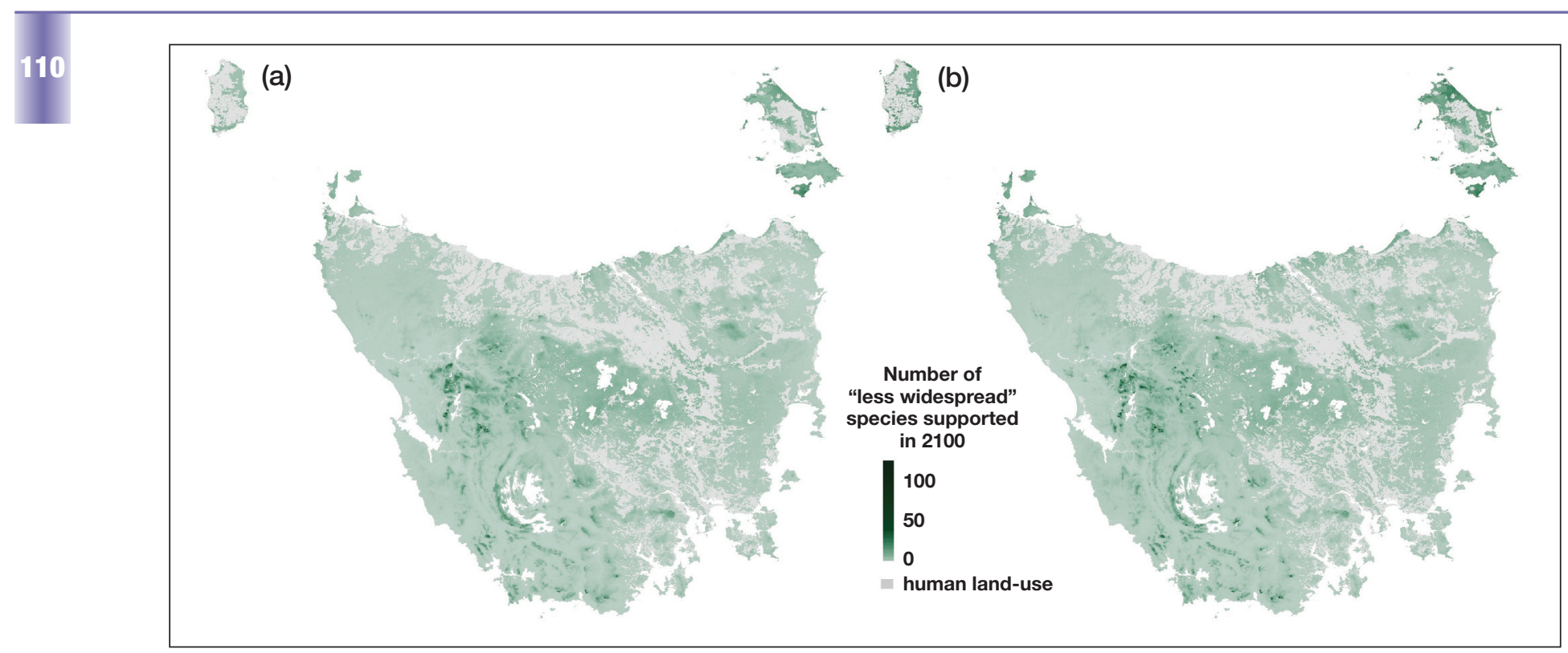

Figure 4. Capacity of refugia, as indicated by the number of "less widespread" plant species (see text for definition) predicted to be supported in each 250-m grid cell across Tasmania in 2100, under climate change, using: (a) the CSIRO mk3.5 (A2 scenario) and (b) the MIROC3.2 global climatic models. Maps illustrating the present distribution of the number of "less widespread" plant species supported in each 250-m grid cell, and the projected change to 2100, are presented in WebFigure 1.

identify both the locations and capacities of climatechange refugia for Tasmanian plant diversity. This combined approach to assess refugial capacity is based on the number and identity of target species predicted to be supported in each assemblage (defined as a 250-m grid cell) in the year 2100 (under climate change), together with the combined size of adjacent cells supporting high species diversity in 2100 . Under this approach, community-level models of species richness ( $\alpha$-diversity) and compositional dissimilarity ( $\beta$-diversity) were fitted, including fine-scale climate, topography, and substrate information. These models were projected spatially, and combined with all available occurrence data to predict the current composition of each grid cell (which is not known for most grid cells) using the DynamicFOAM algorithm (Mokany et al. 2011). These predictions of current assemblage composition then form the initial conditions for the M-SET metacommunity model. M-SET integrates the processes of dispersal and community assembly with future projections of species richness and compositional dissimilarity models to predict change in the composition of each grid cell over time (Mokany et al. 2012). In the present analyses, all 2051 Tasmanian plant species were included in the model, but outcomes were examined only for the less widespread 1538 species.

Assemblages (grid cells) where the largest numbers of lesswidespread species either persisted, or retreated to, by the end of the simulation possessed the greatest capacity as refugia (Figure 4). The modeling approach, which is partially driven by fine-scale environmental conditions and the projected shifts of those conditions under climate change, inherently incorporates environmental stability and microclimatic variation. Furthermore, the model directly includes dispersal processes and metacommunity dynamics, thus accounting for changes in the size and accessibility of habitats over time. In this case, therefore, microclimate variation, environmental stability, size, and accessibility are all directly integrated into the modeling approach, and do not need to be considered separately. The results (Figure 4) allow further assessment of the size of refugia, based on the number of contiguous grid cells of high capacity (Figure 5).

\section{- Prioritization}

Determining when to classify an area as potential refugial habitat needs to be carefully considered for each study, and depends on the target species, the geographical setting, and the predicted intensity of climate change. The highest-capacity refugia can be prioritized for conservation and management to maximize their contribution in supporting biodiversity as the climate changes. However, for conservation planning, additional factors require consideration. These include the economic costs of acquiring and/or managing the land hosting the refugium, social considerations relating to landowners and stakeholders, the integration of the refugium into existing conservation frameworks and priorities, and any degradation or fragmentation due to previous anthropogenic activities (Vos et al. 2008; Klein et al. 2009).

\section{Prioritizing refugia for Tasmanian plant biodiversity}

Our analyses indicate that, for both climate models (CSIRO mk3.5 and MIROC3.2), the highest-capacity refugia for Tasmanian plants under climate change are generally located in higher elevation, topographically complex areas in the southwest portion of the main island in the Tasmanian archipelago (Figure 4). Our results con- 


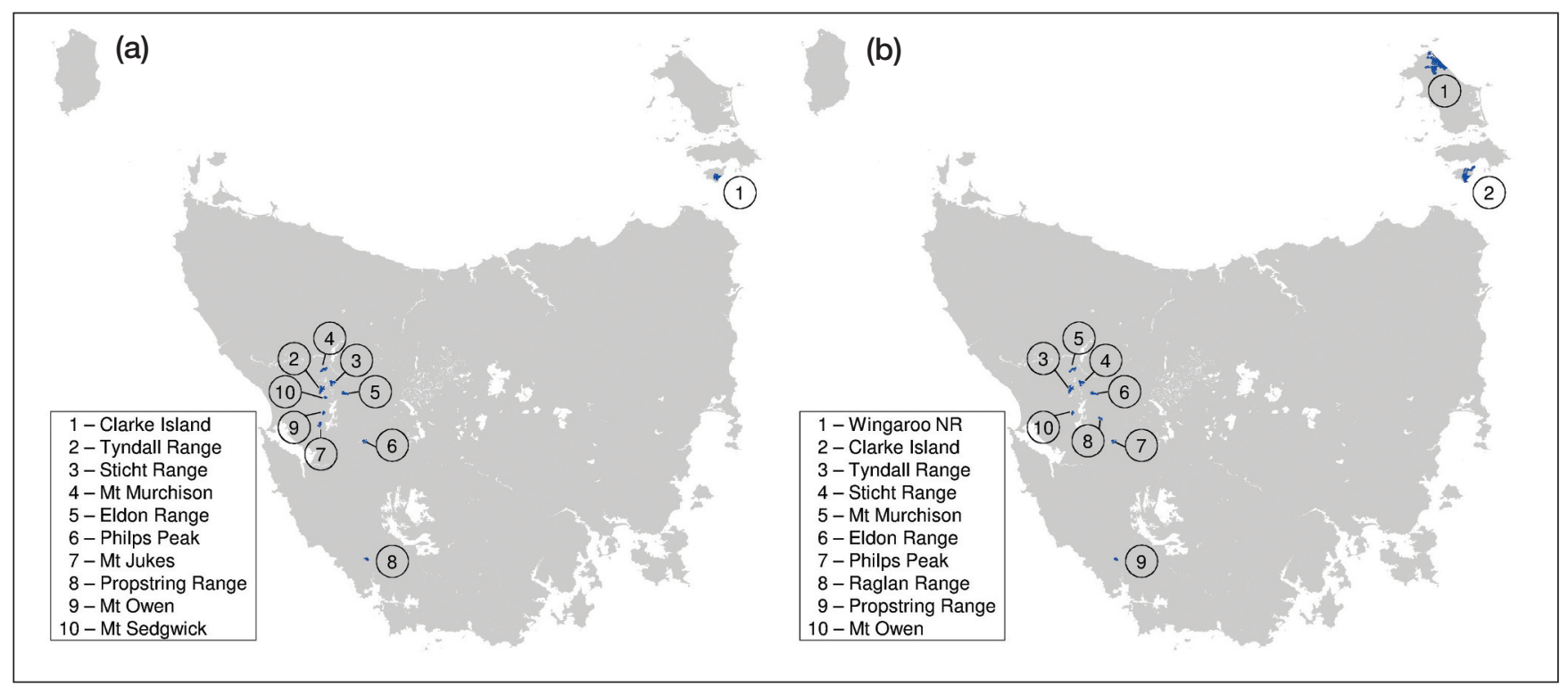

Figure 5. The ten areas of highest capacity as refugia in Tasmania, defined as the largest contiguous areas predicted to support 20 or more of the "less widespread" plant species to 2100, under climate change, using: (a) the CSIRO mk3.5 (A2 scenario) and (b) the MIROC3.2 global climatic models.

cur with the findings of other researchers (eg Ashcroft et al. 2012), who have shown that topographical complexity can indicate locations likely to harbor important future refugia. These topographically complex areas are usually cooler and wetter than their surroundings.

As a simple demonstration of how these projections can be used to identify high-priority areas for conservation and management, we determined the ten largest contiguous areas of high-capacity climate-change refugia for plant diversity in Tasmania (Figure 5). Despite the relatively small area that these high-capacity refugia cover, about $95 \%$ of the "less widespread" plant species are predicted to occur within these ten areas in 2100 (Figure 5). The ten areas occur primarily among contiguous habitat patches within the existing protected area network and provide a focus for ongoing threat management activities (eg controlling alien species, strategic fire management). In the climate model with the mildest temperature projections for 2100 (MIROC3.2), an additional high-priority refugium was located on the smaller islands to the northeast of Tasmania. The greater importance of these smaller islands in milder temperature scenarios was supported when a milder-warming scenario (B1) was applied to the CSIRO mk3.5 model (WebFigure 2).

\section{Discussion}

The framework we describe here quantifies the relative capacity of refugia by integrating information about their environmental stability, microclimatic heterogeneity, size, and accessibility. Together, these form the minimum set of capacity indicators that should be considered, although other factors, such as current level of habitat disturbance, may also be important. A previous attempt to quantify the capacity of refugia focused primarily on environmental stability and microclimatic variability (Ashcroft et al. 2012). Our framework also emphasizes the importance of clearly defining the taxonomic, geographic, and temporal scale of the study.

Our approach integrates outcomes for all species and several capacity indicators. It is therefore unsuitable for discerning the fate of an individual species of particular conservation concern. Species distribution modeling through the use of climate-plus-terrain models, with clear identification of the habitat and dispersal potential of the species (Austin and Van Niel 2011) - would be more appropriate for this purpose.

The degree to which the actual distribution of refugia corresponds with projected distributions will also depend on stochastic factors, especially the interacting influences of disturbance and climate change (Bradstock 2010). In Tasmania, the distribution of rainforest on nutrient-poor soils is related to topographic fire refugia, with topography mediating the fire-vegetation feedbacks that maintain vegetation mosaics (Wood et al. 2011). The evolutionary impacts of fire in our case study have been partially incorporated into the results, because the driving models of species richness and compositional dissimilarity implicitly account for intrinsic relationships between fire and environmental conditions (Bradstock 2010; Wood et al. 2011). Nevertheless, future fire regimes are likely to be quite different from those that currently prevail in the region, adding uncertainty to our projections (Bradstock 2010). The flexible, multidisciplinary approach we propose above helps in quantifying the capacity of refugia, thereby facilitating their integration into conservation planning and modeling. Our case study demonstrates the utility of this framework for defining, identifying, and prioritizing refugia for conserving biodiversity under rapid climate change. 


\section{References}

Ackerly DD, Loarie SR, Cornwell WK, et al. 2010. The geography of climate change: implications for conservation biogeography. Divers Distrib 16: 476-87.

Ashcroft MB. 2010. Identifying refugia from climate change. $J$ Biogeogr 37: 1407-13.

Ashcroft MB, Chisholm LA, and French KO. 2009. Climate change at the landscape scale: predicting fine-grained spatial heterogeneity in warming and potential refugia for vegetation. Glob Change Biol 15: 656-67.

Ashcroft MB, Gollan JR, Warton DI, and Ramp D. 2012. A novel approach to quantify and locate potential microrefugia using topoclimate, climatic stability, and isolation from the matrix. Glob Change Biol 18: 1866-79.

Austin MP and Van Niel KP. 2011. Impact of landscape predictors on climate change modelling of species distributions: a case study with Eucalyptus fastigata in southern New South Wales, Australia. J Biogeogr 38: 9-19.

Bradstock RA. 2010. A biogeographic model of fire regimes in Australia: current and future implications. Global Ecol Biogeogr 19: $145-58$.

Chen I-C, Hill JK, Ohlemüller R, et al. 2011. Rapid range shifts of species associated with high levels of climate warming. Science 333: 1024-26.

Corney SP, Katzfey JJ, McGregor JL, et al. 2010. Climate future for Tasmania: climate modelling technical report. Hobart, Tasmania: Antarctic Climate \& Ecosystems Cooperative Research Centre.

Daly C, Conklin DR, and Unsworth MH. 2010. Local atmospheric decoupling in complex topography alters climate change impacts. Int J Climatol 30: 1857-64.

Dobrowski SZ. 2011. A climatic basis for microrefugia: the influence of terrain on climate. Glob Change Biol 17: 1022-35.

Franklin J, Davis FW, Ikegami M, et al. 2013. Modeling plant species distributions under future climates: how fine scale do climate projections need to be? Glob Change Biol 19: 473-83.

Gaston KJ and Blackburn TM. 1996. Conservation implications of geographic range size-body size relationships. Conserv Biol 10: 638-46.

Grose MR, Barnes-Keoghan I, Corney SP, et al. 2010. Climate futures for Tasmania: general climate impacts technical report. Hobart, Tasmania: Antarctic Climate \& Ecosystems Cooperative Research Centre.

Hampe A and Petit RJ. 2005. Conserving biodiversity under climate change: the rear edge matters. Ecol Lett 8: 461-67.

Keppel G, Van Niel KP, Wardell-Johnson GW, et al. 2012. Refugia: identifying and understanding safe havens for biodiversity under climate change. Global Ecol Biogeogr 21: 393-404.

Keppel G and Wardell-Johnson GW. 2012. Refugia: keys to climate change management. Glob Change Biol 18: 2389-91.

Kirkpatrick JB and Fowler M. 1998. Locating likely glacial forest refugia in Tasmania using palynological and ecological information to test alternative climatic models. Biol Conserv 85: 171-82.

Klein C, Wilson K, Watts M, et al. 2009. Incorporating ecological and evolutionary processes into continental-scale conservation planning. Ecol Appl 19: 206-17.

Kujala H, Burgman MA, and Moilanen A. 2013. Treatment of uncertainty in conservation under climate change. Conserv Lett 6: 73-85.

Lara A and Villalba R. 1993. A 3620-year temperature record from Fitzroya cupressoides tree rings in southern South America. Science 260: 1104-06.

Loarie SR, Carter BE, Hayhoe K, et al. 2008. Climate change and the future of California's endemic flora. PLoS ONE 3: e2502.
Mackey B, Berry S, Hugh S, et al. 2012. Ecosystem greenspots: identifying potential drought, fire, and climate change microrefuges. Ecol Appl 22: 1852-64.

Malcolm JR, Liu C, Neilson RP, et al. 2006. Global warming and extinctions of endemic species from biodiversity hotspots. Conserv Biol 20: 538-48.

McKinnon GE, Jordan GJ, Vaillancourt RE, et al. 2004. Glacial refugia and reticulate evolution: the case of the Tasmanian eucalypts. Philos T Roy Soc B 359: 275-84.

Mokany K and Ferrier S. 2011. Predicting impacts of climate change on biodiversity: a role for semi-mechanistic community-level modelling. Divers Distrib 17: 374-80.

Mokany K, Harwood TD, Overton JM, et al. 2011. Combining $\alpha-$ and $\beta$-diversity models to fill gaps in our knowledge of biodiversity. Ecol Lett 14: 1043-51.

Mokany K, Harwood TD, Williams KJ, and Ferrier S. 2012. Dynamic macroecology and the future for biodiversity. Glob Change Biol 18: 3149-59.

Ohlemüller R, Anderson BJ, Araújo MB, et al. 2008. The coincidence of climatic and species rarity: high risk to small-range species from climate change. Biol Lett 4: 568-72.

Parmesan C and Yohe G. 2003. A globally coherent fingerprint of climate change impacts across natural systems. Nature 421: 37-42.

Reside AE, Welbergen JA, Phillips BL, et al. 2014. Characteristics of climate change refugia for Australian biodiversity. Austral Ecol; doi:10.1111/aec.12146.

Rosenzweig C, Karoly D, Vicarelli M, et al. 2008. Attributing physical and biological impacts of anthropogenic climate change. Nature 453: 353-57.

Sandel B, Arge L, Dalsgaard B, et al. 2011. The influence of Late Quaternary climate-change velocity on species endemism. Science 334: 660-64.

Schut AGT, Wardell-Johnson GW, Yates CJ, et al. 2014. Rapid characterisation of vegetation structure to predict refugia and climate change impacts across a global biodiversity hotspot. PLOS ONE 9: e82778.

Solomon S, Qin D, Manning M, et al. (Eds). 2007. Summary for policy makers. In: Climate change 2007: the physical science basis. Contribution of Working Group I to the fourth assessment report of the Intergovernmental Panel on Climate Change. Cambridge, UK: Cambridge University Press.

Stewart JR, Lister AM, Barnes I, and Dalén L. 2010. Refugia revisited: individualistic responses of species in space and time. $P R$ Soc B 277: 661-71.

Storlie CJ, Phillips BL, VanDerWal J, and Williams SE. 2013. Improved spatial estimates of climate predict patchier species distributions. Divers Distrib 19: 1106-13.

Svenning J-C and Skov F. 2007. Could the tree diversity pattern in Europe be generated by postglacial dispersal limitation? Ecol Lett 10: 453-60.

Thomas CD, Cameron A, Green RE, et al. 2004. Extinction risk from climate change. Nature 427: 145-48.

Vos CC, Berry P, Opdam P, et al. 2008. Adapting landscapes to climate change: examples of climate-proof ecosystem networks and priority adaptation zones. J Appl Ecol 45: 1722-31.

Weiss SB, Murphy DD, and White RR. 1988. Sun, slope, and butterflies: topographic determinants of habitat quality for Euphydryas editha bayensis. Ecology 69: 1486-96.

Williams JW, Jackson ST, and Kutzbach JE. 2007. Projected distributions of novel and disappearing climates by 2100 AD. P Natl Acad Sci USA 104: 5738-42.

Wood SW, Murphy BP, and Bowman DMJS. 2011. Firescape ecology: how topography determines contrasting distribution of fire and rain forest in the south-west of the Tasmanian Wilderness World Heritage Area. J Biogeogr 38: 1807-20. 